\title{
Drug Targets for Corona Virus (COVID-19): A Systematic Review
} Jayakumar K*

Professor and Head, Department of Biochemistry, PMS College of Dental Science and Research, Vettapara, Thiruvanthapuram, Kerala, India

DOI: $10.36348 /$ sijb.2020.v03i06.005

| Received: 20.06.2020 | Accepted: 27.06.2020 | Published: 30.06 .2020

*Corresponding author: Dr. Jayakumar K

\section{Abstract}

The 2019-novel corona virus (nCoV) is a major source of disaster in the 21th century. However, the lack of specific drugs to prevent/treat an attack is a major need at this current point of time. In this regard, we conducted a systematic review to identify major drug gable targets in corona virus $(\mathrm{CoV})$. We searched PubMed and RCSB database with keywords HCoV, NCoV, corona virus, SERS-CoV, MERS-CoV, 2019-nCoV, crystal structure, X-ray crystallography structure, NMR structure, target, and drug target till Feb 3, 2020. The search identified seven major targets (spike protein, envelop protein, membrane protein, protease, nucleocapsid protein, hemagglutinin esterase, and helicase) for which drug design can be considered. There are other 16 nonstructural proteins (NSPs), which can also be considered from the drug design perspective. The major structural proteins and NSPs may serve an important role from drug design perspectives. However, the occurrence of frequent recombination events is a major deterrent factor toward the development of CoVspecific vaccines/drugs.

Keywords: Corona virus, drug targets, Middle East respiratory syndrome, severe acute respiratory syndrome.

Copyright @ 2020: This is an open-access article distributed under the terms of the Creative Commons Attribution license which permits unrestricted use, distribution, and reproduction in any medium for non-commercial use (NonCommercial, or CC-BY-NC) provided the original author and source are credited.

\section{INTRODUCTION}

Corona viruses (CoVs) have a single-stranded RNA genome (size range between 26.2 and $31.7 \mathrm{~kb}$, positive sense), covered by an enveloped structure. The shape is either pleomorphic or spherical, and it is characterized by bears club-shaped projections of glycoproteins on its surface (diameter 80-120 nm) [1]. Among all the RNA viruses, the RNA genome of $\mathrm{CoV}$ is one among the largest. The number of open reading frames (ORFs) in the $\mathrm{CoV}$ genome ranges from six to ten [2]. CoV genetic material is susceptible for frequent recombination process, which can give rise to new strains with alteration in virulence [3]. There are seven strains of human CoVs, which include 229E, NL63, OC43, HKU1, Middle East respiratory syndrome (MERS)-CoV, severe acute respiratory syndrome (SARS)-CoV, and 2019-novel corona virus (nCoV), responsible for the infection with special reference to the involvement of the respiratory tract (both lower and upper respiratory tract), e.g., common cold, pneumonia, bronchiolitis, rhinitis, pharyngitis, sinusitis, and other system symptoms such as occasional watery and diarrhea [4]. Among these seven strains, three strains proved to be highly pathogenic (SARS-CoV, MERS$\mathrm{CoV}$, and 2019-nCoV), which caused endemic of severe CoV disease [5]. The reservoir of SARS-CoV is unknown, but bats and subsequent spread to Himalayan palm civets are hypothesized [6]. MERS-CoV also has a zoonotic origin in the Middle East, and the transmission is through camels [7]. Among these, the SARS-CoV outbreak started in 2003 in Guangdong province of China and the second outbreak of the MERS-CoV outbreak in 2012 in Saudi Arabia. Previous to these two attacks, CoV was known to cause milder disease, and these two outbreaks highlighted their adaptive potential to the changing environmental conditions and they are classified under "emerging viruses." Knowledge about the structure, metabolic pathways of $\mathrm{CoV}$, and pathophysiology of $\mathrm{CoV}$ associated diseases is important to identify possible drug targets [8].

The most important structural proteins of $\mathrm{CoV}$ are spike $(\mathrm{S})$ protein (trimeric), membrane $(\mathrm{M})$ protein, envelop (E) protein, and the nucleocapsid (N) protein. Some of the viruses such as beta-CoVs also have hemagglutinin esterase (HE) glycoprotein. The RNA genome of $\mathrm{CoV}$ has seven genes that are conserved in the order: ORF1a, ORF1b, S, OEF3, E, M, N in 5' to 3' direction. The two-third part of the RNA genome is covered by the ORF1a/b, which produces the two viral replicase proteins that are polyproteins (PP1a and PP1ab) [9]. Sixteen mature nonstructural proteins (NSPs) arise from further processing of these two PPs. These NSPs take part in different viral functions 
including the formation of the replicase transcriptase complex. The remaining genome part of the virus encodes the mRNA which produces the structural proteins, i.e., spike, envelope, membrane, and nucleocapsid, and other accessory proteins. Another important envelop-associated protein which is expressed by only some strains of $\mathrm{CoV}$ is the $\mathrm{HE}$ protein [10]. The RNA genome of $\mathrm{CoV}$ is packed in the nucleocapsid protein and further covered with envelope [11].

\section{Molecular Basics of Transmission of Corona virus} In case of SARS-CoV, transmission is through droplet infection (respiratory secretions) and close person-to-person contact. It can also spread through sweat, stool, urine, and respiratory secretions. When virus enters into the body, it binds to the primary target cells such as enterocytes and pneumocytes, thereby establishing a cycle of infection and replication. Other target cells of $\mathrm{CoV}$ are epithelial renal tubules, tubular epithelial cells of kidney, immune cells, and cerebral neuronal cells [11-13]. CoV attaches to the target cells with the help of spike protein-host cell protein interaction (angiotensin converting enzyme-2 [ACE-2] interaction in SARS-CoV [14] and dipeptidyl peptidase-4 [DPP-4] in MERS-CoV) [15]. After the receptor recognition, the virus genome with its nucleocapsid is released into the cytoplasm of the host cells. The viral genome contains ORF1a and ORF1b genes, which produce two PPs that are pp1a and pp1b which help to take command over host ribosomes for their own translation process. Both pp1a and pp1b take part in the formation of the replication transcription complex.After processing of PP by protease, it produces 16 NSPs. All NSPs have their own specific functions such as suppression of host gene expression by NSP1 and NSP2, formation of a multidomain complex by NSP3, NSP5 which is a M protease which has role in replication, NSP4 and NSP6 which are transmembrane (TM) proteins, NSP7 and NSP8 which act as a primase, NSP9-a RNA-binding protein, the dimeric form of which is important for viral infection. Induction of disturbance to the dimerization of NSP9can be a way to overcome CoV infection [16-20]. NSP10 acts as a cofactor for the activation of the replicative enzyme. NSP12 shows RNA-dependent RNA polymerase activity, NSP13 shows helicase activity, NSP14 shows exoribonuclease activity, NSP15 shows endoribonuclease activity, and NSP16 has methyltransferase activity. All NSPs have an important role in replication and transcription [21].

Synthesized proteins such as $\mathrm{M}, \mathrm{E}$, and $\mathrm{S}$ are entered into the endoplasmic reticulum (ER)-Golgi intermediate compartment (ERGIC) complex and make the structure of viral envelope. On the other hand, the replicated genome binds to $\mathrm{N}$ protein and forms the ribonucleoprotein (RNP) complex. The outer cover is formed by the M, E, and S proteins. Finally, the virus particle comes out of the ERGIC by making a bud-like structure. These mature virions form a vesicle, which fuses with the plasma membrane and releases the virus particles into the extracellular region [22-24]. The detailed structure of $\mathrm{CoV}$ and its life cycle is depicted in (Figure $1 \& 2$ ). On infection, the SARS-CoV and MERS-COV cause a surge of pro-inflammatory cytokines and chemokines, which cause damage to lung tissue, deterioration of lung function, and then finally lung failure in some cases [25]. The $\mathrm{S}$ proteins of $\mathrm{CoV}$ binds to cellular receptor angiotensin-converting enzyme 2 (ACE2) which is followed by entry of the viral RNA genome into the host cell and translation of structural and non structural proteins (NSP) follows. ORF1a and ORF1ab are translated to produce ppla and pp1ab polyproteins, which are cleared by the proteases that are encoded by ORF1a to yield 16 non-structural proteins. This is followed by assembly and budding into the lumen of the ERGIC (Endoplasmic Reticulum Golgi Intermediate Compartment). Virions are then released from the infected cell through exocytosis. S: spike, E: envelope, $\mathrm{M}$ : membrane, $\mathrm{N}$ : nucleocapsid. PP: polyproteins, ORF: Open reading frame, CoV: coronavirus (Figure 1 and 2).

Currently, there is no specific antiviral drug for the treatment of $\mathrm{CoV}$-associated pathologies. Most treatment strategies focus on symptomatic management and supportive therapy only [26, 27]. Some therapeutic agents that are under development or being used offlabel are ribavirin, interferon (IFN)- $\alpha$, and mycophenolic acid. There are many newspaper articles citing effectiveness of anti-HIV drugs: ritonavir, lopinavir, either alone or in combination with oseltamivir, remdesivir, and chloroquine and among these, ritonavir, remdesivir, and chloroquine showed efficacy at cellular level which further need experimental support and validation [28, 29]. As there is no well-defined therapy available, which specifically targets $\mathrm{CoV}$, in this article, we have reviewed the possible protein structures, which could be potential targets for the development of a therapeutic approach for the treatment of $\mathrm{CoV}$.

\section{MATERIALS AND METHODS Database Screen}

We screened PubMed and RCSB database with the keywords $\mathrm{HCoV}, \mathrm{NCoV}$, corona virus, SERSCoV, MERS-CoV, 2019-nCoV, crystal structure, X-ray crystallography structure, NMR structure, target, and drug target till Feb 3, 2020. The database files were extracted using endnote, and title and abstract screening was done using Rayyan QCRI. Full texts of these screened articles were further screened for possible inclusion in the systematic review. Articles that evaluated different druggable targets of $\mathrm{CoV}$ and evaluated different therapeutic measures against some identifiable target were included for further review. 


\section{RESULTS AND DISCUSSION}

A total of 392 articles were found after preliminary screening of the databases. After title and abstract screening, a total of 230 articles were excluded. Full-text screening of the remaining 154 articles was done. Among these studies, after full-text screening, a total of 122 articles were included in the final review.
The PRISMA flowchart of the study is shown in (Figure-3). Thirty-two articles were excluded after fulltext screen (review articles $=7$, articles not specifying drug targets against $\mathrm{CoV}=22$, articles in other language other than English = 3). Details of studies with important structural and functional target proteins are summarized in (Table-1 and Flow Chart-1).

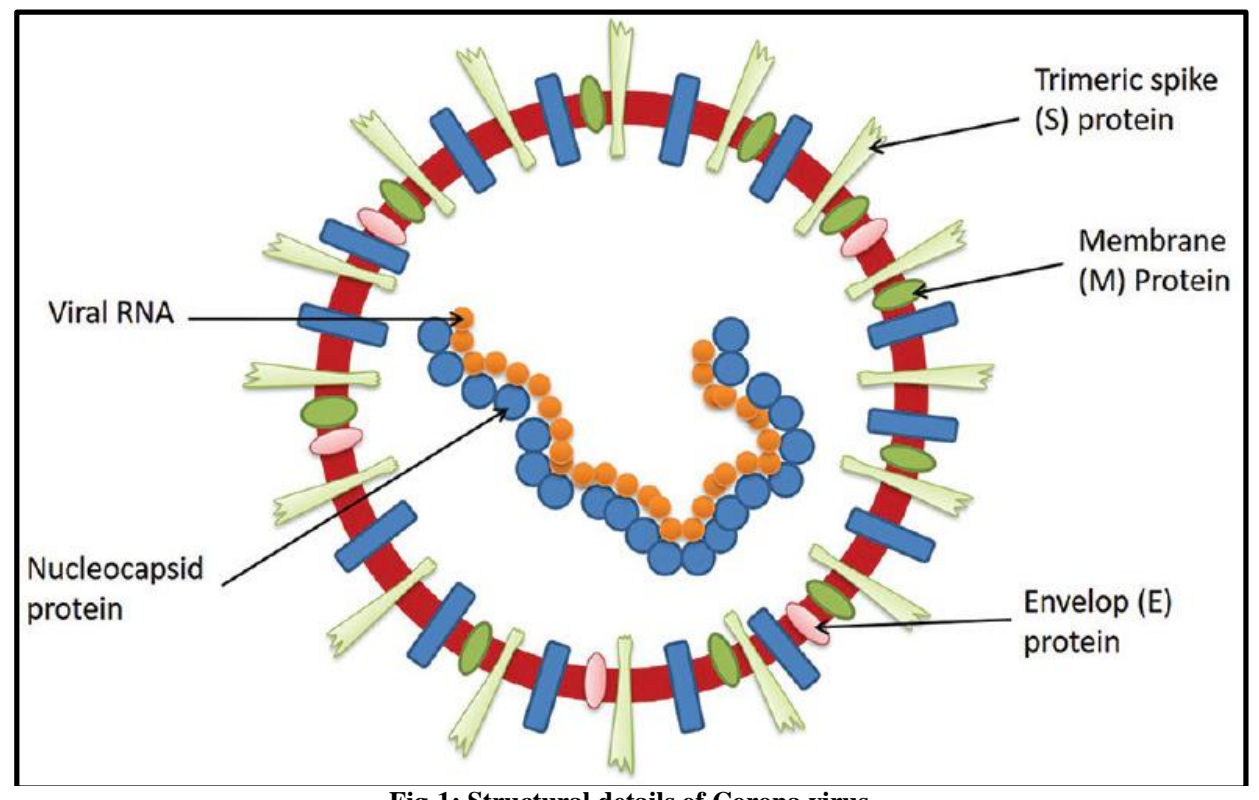

Fig-1: Structural details of Corona virus

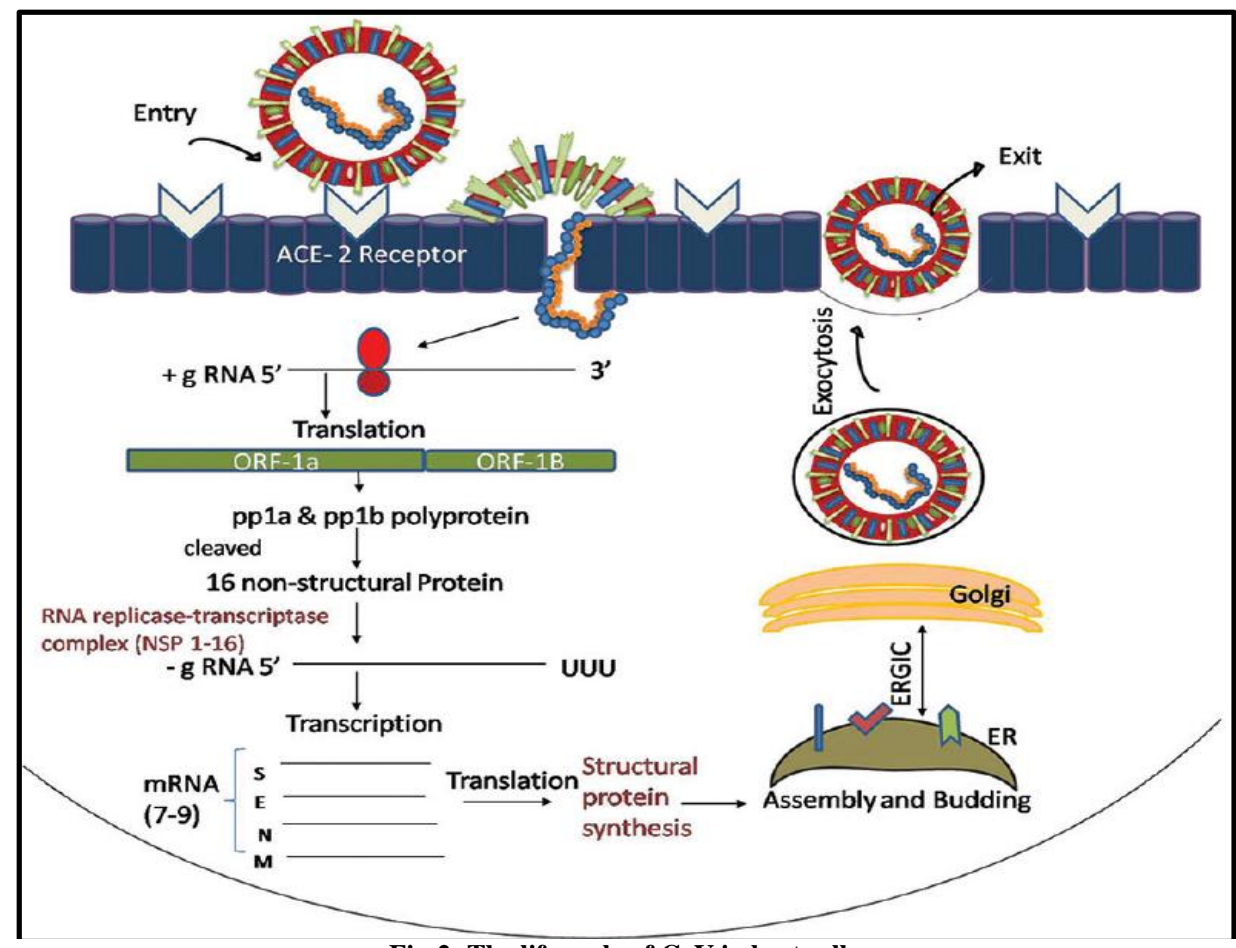

Fig-2: The life cycle of $\mathrm{CoV}$ in host cells 


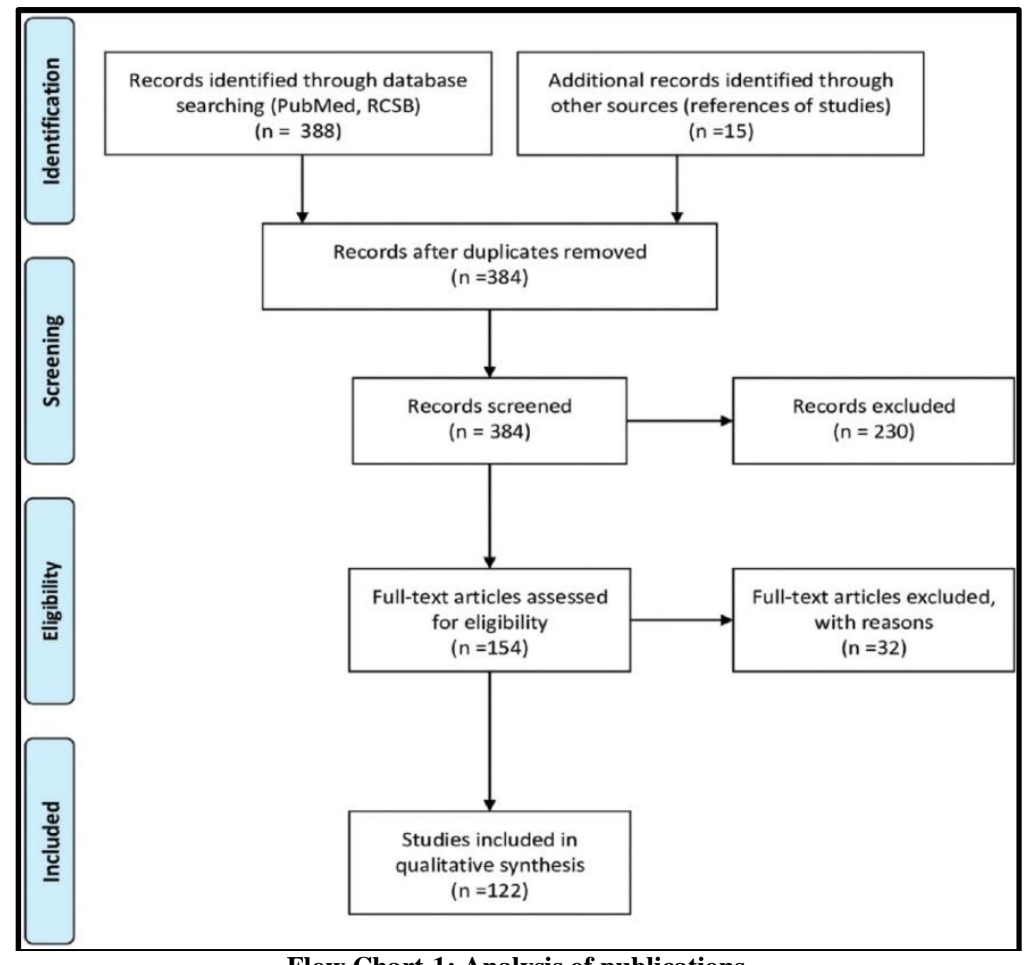

Flow Chart-1: Analysis of publications

Table-1: Details of various protein inhibitors

\begin{tabular}{|c|c|c|c|c|}
\hline PDB ID & Details & Inhibitor & $\mathrm{IC}_{50}$ & Reference \\
\hline \multicolumn{5}{|c|}{$\mathrm{N}$ protein } \\
\hline $4 \mathrm{KXJ}$ & $\begin{array}{l}\text { Interaction between PJ34 and NTD of N protein of } \\
\text { HCoV-OC43 }\end{array}$ & PJ34 & - & [26] \\
\hline $3 \mathrm{~V} 3 \mathrm{P}$ & Structure not released & & & [30] \\
\hline 4LM7 & Interactions of NTD of N protein of HCoV-OC43 with UMF & & & [26] \\
\hline $4 \mathrm{LI} 4$ & Interactions of NTD of N protein of $\mathrm{HCoV}-\mathrm{OC} 43$ with AMP & & & [26] \\
\hline \multicolumn{5}{|c|}{ Protease } \\
\hline 4TWY & 3CLPro of SARS-GoV with an inhibitor & $3 \mathrm{BL}$ & & [27] \\
\hline 4TWW & 3CLPro of SARS-GoV with an inhibitor & 41 & $63 \mu \mathrm{M}$ & [27] \\
\hline $4 W Y 3$ & 3CLPro of SARS-GoV with an inhibitor & $3 \times 5$ & $240 \mu \mathrm{M}$ & [27] \\
\hline $40 V Z$ & CoV PLPro complexed with inhibitor & P85 & $490 \mathrm{nM}$ & [31] \\
\hline 3MJ5 & SARS-CoV PL Pro complexed with inhibitor & GRM & $320 \mathrm{nM}$ & [32] \\
\hline 2FE8 & SARS-CoV PL Pro & - & - & [33] \\
\hline $1 \cup K 4$ & SARS-CoV $3 \mathrm{CL}^{\text {Pro }}$ and its interactions with an inhibitor & Substrate analog hexapeptidyI CMK inhibitor & $\mathrm{IC}_{50}$ ca. $2 \mathrm{mM}$ & [34] \\
\hline $\begin{array}{l}\text { 1UJ1, } \\
\text { 1UK3, 1UK2 }\end{array}$ & SARS-CoV M-pro, apo-enzyme at different pH & - & - & [34] \\
\hline 3VB6 & SARS-CoV 3CLPro in complex with C6Z & $\mathrm{C} 6 \mathrm{Z}$ & $39 \mu \mathrm{M}$ & [35] \\
\hline $3 \mathrm{VB} 5$ & SARS-CoV 3CLPro with C4Z & $\mathrm{C} 4 \mathrm{Z}$ & $1.3-4.6 \mu \mathrm{M}$ & [35] \\
\hline 3TLO & HCoV-NL63 3CLPro & - & - & {$[36,37]$} \\
\hline 6LU7 & $\begin{array}{l}\text { Main protease of 2019-nCoV and its complex with N3 } \\
\text { (inhibitor) }\end{array}$ & - & - & [38] \\
\hline \multicolumn{5}{|c|}{ Spike protein } \\
\hline 5ZUV & HR1 motif of HCoV-229E in complex with EK1 & Modified OC43-HR2P peptide (EK1) & $0.19-0.62 \mu \mathrm{M}$ & [39] \\
\hline $5 Z \mathrm{VM}$ & EK1 in complex with SARS HR1 motif & & & [39] \\
\hline $5 \times 4 S$ & NTD of SARS-CoV S protein & & & [40] \\
\hline 5WRG & SARS-CoV S protein & & & [41] \\
\hline $6 Q 05$ & MERS-CoV S structure in complex with Sialyl-Lewis & & & [42] \\
\hline 6ACG & SARS-CoV S protein: ACE-2 (conformation 1) complex & & & [43] \\
\hline 6ACK & SARS-CoV S protein: ACE-2 (conformation 3) complex & & & [43] \\
\hline $3 \mathrm{SCl}$ & RBD of $S$ protein interaction with ACE-2 & & & $\begin{array}{l}\text { [44] to be } \\
\text { published }\end{array}$ \\
\hline
\end{tabular}

\section{Spike Protein}

The spike protein is a clove-shaped, type I-TM protein. The spike protein has three segments that are ectodomain (ED) region, TM region, and intracellular domain, which comprises the intracellular short tail part. The receptor-binding S1 domain (three S1 heads) and the membrane fusion subunit $\mathrm{S} 2$ (trimeric stalk) on C-terminal together comprise the ED. Spike proteins gather in the trimeric form on the outer surface of the virion, giving it the appearance of a crown, due to 
which it is called CoV. The spike protein plays an important role in virus entry into the host. Initial interactions between the $\mathrm{S} 1$ domain and its host receptor (ACE2 in case of SARS-CoV and PP 4 In case of MERS-CoV) and subsequent S2 segment mediated fusion of the host and viral membranes allow the CoVRNA genome to enter inside the host cells and thus, these proteins represent as important targets from drug discovery side. The spike protein also activates the immune response of the host cell toward $\mathrm{CoV}[2,10]$.

\section{S1 Domain}

The main components of the S1 domain are the N-terminal domain (NTD) and the C-terminal domain (CTD). The $\mathrm{S} 1$ domain acts as a major antigen on the surface of the virus [40] and has a receptorbinding domain (RBD). The 18 residues of ACE-2 interact with the RBD (contain 14 amino acids) of SARS-CoV spike protein, and for this contact, K341 of ACE-2 and R453 residue of RBD play the most important role. If point mutated on the D454 or R441 of $\mathrm{RBD}$, it disturbs the binding activity with ACE-2. The S1 domain interacts with the ACE-2 or DPP-4 receptors of the host. Anti-ACE-2 antibody blocked viral entry and replication in Vero E6 cells. One another mechanism of virus for binding to host cell is using dendritic cell-specific intercellular adhesion molecule-3 grabbing non-integrin (DC-SIGN receptor) or L-SIGN in lymph nodes or in liver. S-protein has seven (109, 118, 119, 158, 227, 589, and 699) glycosylation asparagine-linked sites, which is pivotal for both LSIGN- or DC-SIGN-based virus entry into the host [14, 25, 45-47].

\section{S2 Subunit}

The S2 subunit has two heptad repeat regions (HR 1 and 2) and hydrophobic fusion peptide. Drug designing strategies targeting $\mathrm{S}$ protein and its interactions. The RBD is targeted in many drug designing studies. A peptide sequence with sequence similarity to the RBD of S protein hampered S1-RBD: ACE-2 interaction and prevented entry of SARS-CoV into Vero cells (IC50 around $40 \mu \mathrm{M}$ ). A SARS-CoV RBD-specific antibody (FM6) failed to inhibit the occurrence of infection. OC43-HR2P, a peptide derived from heptad repeat 2 regions of $\mathrm{S} 2$ domain of $\mathrm{HCoV}$ OC43 and its optimized form EK1, showed pan-CoV fusion inhibition property. The structure (protein data bank [PDB] ID 5ZUV and 5ZVM) shows as -helix bundle structure with $\alpha-\mathrm{HCoV}$ and long $\beta-\mathrm{HCoV}-\mathrm{HR} 1$ domain. Chloroquine, an antimalarial agent, inhibits SERS-CoV by elevation of endosomal $\mathrm{pH}$ and alters the terminal glycosylation of ACE-2, which ultimately interferes with the virus receptor binding. Other inhibitors SSAA09E2 block the S-ACE2 interaction, SSAA09E1 inhibits the host protease cathepsin L (which is important for viral entry), and SSAA09E3 prevents fusion of host and viral cell membrane [25, 49, 50, 39, 51, 52]. Kao et al., identified 18 small molecules that targeted the S-ACE-2-mediated entry of virus into human cell. In 293 T cells expressing ACE-2, one of these agents (VE607) showed a significant inhibition of SARS-pseudovirus entry. In Vero E6 cells, two other molecules tetra-O-galloyl beta-D-glucose and luteolin also inhibited SARS-pseudovirus and SARS$\mathrm{CoV}$ infection. In virus-infected Vero E6 cells, a siRNA against the $\mathrm{S}$ sequences of SARS-CoV inhibited SARSCoV replication $[53,54]$.

The S230 antibody (origin: memory B-cells of SARS-CoV-infected persons) neutralizes wide spectrum of isolates of SARS-CoV. S230 antibody Fab fragment binds to the SARS-CoV complex to neutralize it, and their structures are also available (PDB IDs: 6NB6, 6NB7, and 6NB8.The monoclonal antibody, m396, has a competitive role for RBD binding (PDB ID: 2DD8) [55, 56]. Monoclonal antibody can be generated by immunizing the spike protein of SERS$\mathrm{CoV}$ (transgenic mice) or from the B-cells of CoVinfected persons. Spike-specific monoclonal antibodies 80R and CR301 block the S-ACE-2 interactions and thus neutralize infection by human SARS-CoV (HKu39849 and Tor2) and palm civet strain (SZ3). Mice vaccinated with SARS-n DNA showed T-cell immune response (both induction and proliferation), and cytotoxic T-cell response was seen against SARSDNA-transfected alveolar epithelial cells [57].

\section{Envelop Protein (E)}

The E protein is the smallest (8.4-12 kDa size) TM structural protein of CoV. Two distinct domains comprise the E protein: the hydrophobic domain and the charged cytoplasmic tail. However, the structure is highly variable among different members of the $\mathrm{CoV}$ family. The $\mathrm{E}$ protein has a special role in viral morphogenesis, especially during assembly and egress. CoVs lacking $\mathrm{E}$ protein show lower viral titer, immature, and inefficient progenies. Oligomerization of $\mathrm{E}$ proteins leads to the formation of ion channels. However, the importance of these ion channels is still not clear. Many other studies infer that the E protein acts in coordination with other intracellular proteins and modulates the activity of those proteins. E protein also acts as a virulence factor. E protein has an important role in $\mathrm{CoV}$ assembly and budding formation. Apart from this, E protein found around the ER and Golgi body regions. Hexamethyleneamiloride blocks this $\mathrm{E}$ protein-associated ion channel activity in the mammalian cells expressing SERS-CoV envelop protein [59-62].

\section{Membrane Protein}

Maintenance of the shape of the viral envelope is the most important function of the $\mathrm{M}$ protein, and the $\mathrm{M}$ protein performs this job by interacting with other $\mathrm{CoV}$ proteins, incorporation of Golgi complex into new virions, and stabilization of nucleocapsid protein. The $M$ protein is characterized by three TM domains with C-terminal inside (long) and N-terminal (short) outside. The details of the protein structure is available in 
UniProt. Through multiple protein-protein interactions, the $\mathrm{M}$ protein plays a crucial role in viral intracellular homeostasis. Interaction between $\mathrm{M}-\mathrm{M}, \mathrm{M}-\mathrm{S}$, and $\mathrm{M}-$ $\mathrm{N}$ proteins takes a special part in viral assembly. The $\mathrm{M}-\mathrm{S}$ interactions are necessary for the interaction of spike protein in the ERGIC complex, also known as the Golgi complex, which is later incorporated into new viral progenies. The $\mathrm{M}-\mathrm{N}$ interactions are crucial for the stabilization of the RNP complex (nucleocapsidRNA complex), which forms the viral core. The $\mathrm{M}$ protein and the $\mathrm{N}$ protein are the major viral envelope proteins, defining viral shape, but it also takes part in the formation and release of virus-like particles [63, 64]. $M$ protein also takes part in the sensitization of the host by the virus. The $M$ protein of SARS-CoV activates the nuclear factor kappa pathway and IFNbeta pathway, through a Toll-like receptor-dependent mechanism. Again, a mutated M protein (V-68) failed to illicit an IFN-beta response [66]. Mice vaccinated with SARS-M DNA showed T-cell immune response (both induction and proliferation), and cytotoxic T-cell response was seen against SARS-DNA-transfected alveolar epithelial cells [57].

\section{Nucleocapsid Protein (N)}

The structure of nucleocapsid protein ( $\mathrm{N}$ protein) is conserved across different members of the $\mathrm{CoV}$ family. The three characteristic intrinsically disordered regions (IDRs) of the nucleocapsid (N) protein are the $\mathrm{N}$-arm, central linker (CL), and the $\mathrm{C}$ tail. The NTD and the CTD are the major structural and functional domain of the nucleocapsid protein. The most important function of the N protein NTD is RNA binding, while the primary job of the CTD is dimerization. As the CL region is rich in arginine and serine residue content, it also contains a large number of phosphorylation sites. The C-terminal IDRs take an important part in nucleocapsid protein oligomerization and $\mathrm{N}-\mathrm{M}$ protein interactions [67]. Formation and maintenance of the RNP complex are the most important functions of the $\mathrm{N}$ protein. It also regulates the replication and transcription of viral RNA, and in the host, it inhibits protein translation through EF1 $\alpha$ mediated action, alteration of host cell metabolism, host cell cycle ( $\mathrm{N}$ proteins are reported to inhibit CDK4), and apoptosis. In human peripheral blood, $\mathrm{N}$ protein inhibits cell proliferation through the inhibition of cytokinesis $^{68}$. The NTD contains sites for RNA binding. The RNA-binding sites on the NTD of N protein were identified by observing its interactions with ribonucleoside 5'-monophosphates (AMP, UMP, CMP, and GMP). Using the information about interaction between AMP and UMP binding to the NTD of nucleocapsid protein, inhibitors of RNA binding were designed. Three-dimensional structure with all complex can see from PDB that is 4LMC, 4LM9, 4LM7, and 4LI4, respectively. One such molecule which was designed with this strategy is $\mathrm{N}$-(6-oxo-5,6dihydrophenanthridine-2-yl) (N, N dimethyl amino) (PJ34), which was designed using the HCoV-OC43 model. Binding of PJ34 on NTD affects the genome binding and replication process of $\mathrm{CoV}$. The crystal structure of COV-OC43 N-NTD with inhibitor PJ34 complex is given in PDB ID: 4KXJ. On the basis of interactions between PJ34 and NTD of nucleocapsid protein, another inhibitor was designed that is H3 (6chloro-7-(2-morpholin-4-yl-ethylamino) quinoxaline5,8-dione), which also inhibits RNA binding. This highlights the importance of NTD in RNA binding. Some of the herbal products, such as catechingallate and gallocatechingallate (both are polyphenolic compounds), have shown the inhibitory action against SARS-CoV [69, 70]. The CTD of $\mathrm{N}$ protein has a primary role in oligomerization, especially the $\mathrm{C}$ terminal end. A C-terminal tail peptide sequence N377389 competes with the oligomerization process and significant inhibition of viral titer was seen at $300 \mu \mathrm{M}$ concentration [71]. N220, which is a nucleocapsid protein peptide, showed a high binding affinity to human MHC-1 in T2 cells, and the peptide sequence was successful in activating T-cells (cytotoxic). In transgenic animals, the peptide further showed potential to selective killing of nucleocapsid protein expressing cells and is a potential candidate for DNA vaccine. Other $\mathrm{N}$ protein-targeted peptides of importance are NP111, NP331, and NP351 [72, 73].

\section{Proteases}

The SERS-CoV genome encodes a number of proteins. The replicase gene, which is a major component of the CoV genome encoded for 16 NSPs in the form of two large PPs (PP1a and PP1ab). Two types of cysteine proteases act on these PPs to release the NSPs. The C-terminal end of these PPs is cleaved by chymotrypsin-like cysteine protease (main protease [Mpro] or 3C-like protease [3CLpro]) and the $\mathrm{N}$ terminal end is processed by the Mpro (also known as papain-like protease [PLpro]) [74]. The first three cleavage sites of the PPs is cut by PLpro while the rest 11 sites are cleaved by CLpro, and this cleavage results in release of 16 NSPs [74, 75].

\section{C-Like Protease}

The 3CLpro is present in homodimer form and has cys-his dyad on active site which shows protease activity. If mutated on the Ser139 and phe140 positions, it abolishes the dimerization of 3CLPro (PDB ID: 3F9G). This protease can cleave 11 sites in the p1 position of PP1a and PP1ab and can produce a mature protein that anchors the replication/transcription complex and also releases the mature NSPs [76-78]. N(benzo [1, 2, 3] triazol-1-yl)-N-(benzyl) acetamido) phenyl) carboxamides are also found to be important inhibitors of CLPro. The structure of CLPro inhibitor is with ML188 (IC50 $1.5 \mu \mathrm{M}$ ) is reported (CID: 46897844, PDB ID: 3V3M). Another structure with CLPro inhibitor ML300 (PDB ID: 4MDS, IC50: 6.2 $\mu \mathrm{M})$ is reported. Some metal-conjugated and peptidomimetic compounds showed inhibitory activity against 3CLpro. Some of the small molecules also act 
as an inhibitor that is arylboronic acids, quinolinecarboxylate derivatives, thiophenecarboxylate, and phthalhydrazide-substituted ketoglutamine analogs. Some flavonoids are also reported to inhibit Mpro [75]. GC376 also has protease inhibitor activity. A crystal structure of Mpro with small molecule inhibitor N3 is also reported (PDB ID: 2AMQ). Lopinavir and ritonavir, which are the inhibitors of HIV protease, also inhibit Mpro. In silico studies directed that among commercially available drugs, colistin, valrubicin, icatibant, bepotastine, epirubicin, epoprostenol, vapreotide, aprepitant, caspofungin, and perphenazine also bind to the lopinavir/ritonavir-binding site on $\mathrm{CoV}$ [79-82].

\section{Papain-Like Protease}

The PLpro cleaves the N-terminal region of the PP to generate three NSPs (NSP 1, 2, and 3). PLpro has a catalytic core domain that contains 316 amino acid, which is responsible for cleaving replicase substrates, and a consensus sequence LXGG was required for cleavage. Higher doses of zinc and zinc conjugates were found to inhibit both types of SARS protease (CLpro and PLpro). Benzodioxole can inhibit the PLpro enzyme. The crystal structure of interaction is shown in PDB ID: 4OVZ, 4OWZ. Through in silico approach, another new lead was identified (6577871) which was further optimized, and compound $15 \mathrm{~h}(\mathrm{~S}$ configuration, enzyme IC50 $=0.56 \mu \mathrm{M}$, antiviral EC50 $=9.1 \mu \mathrm{M}$ ) and $15 \mathrm{~g}$ ( $\mathrm{R}$ configuration, enzyme IC50 $=0.32 \mu \mathrm{M}$; antiviral EC50 $=9.1 \mu \mathrm{M}$ ) were found to be the most important inhibitors. The crystallized structural details of these interactions can be visualized in the PDB database (PDB ID: 2FE8 and 3E9S) [83, 84]. Many of the protease inhibitors are being used in the treatment of COVID-19, e.g., lopinavir-ritonavir combinations [85].

\section{Hemagglutinin Esterase}

This HE enzyme is present in the envelope of $\mathrm{CoV}$, more specifically among beta-coronaviridiae. The $\mathrm{HE}$ is a marker of $\mathrm{CoV}$ and influenza virus evolution. $\mathrm{HE}$ mediates reversible attachment to O-acetylatedsialic-acids by acting both as lectins and as receptordestroying enzymes. Interactions between $\mathrm{HE}$ in complex with sialic acid can be visualized in PDB ID: 3CL5 [86].

\section{NTPase/helicase}

NTPase/helicase plays an important role in the central dogma of the virus. SARS-CoV helicase enzyme is a member of the SF1. This enzyme prefers ATP, dATP, and dCTP as substrates; it also hydrolyzed all NTPs. Toxicity issues are main obstacles in the development of inhibitors of helicase, and nonspecificity of inhibitors may cause serious toxicity [87]. However, despite theoretical limitations, helicase is being increasingly recognized as a druggable target for different disease conditions [87-89]. Once entered into the host cell, the subsequent life cycle of SERS-
$\mathrm{CoV}$ requires low $\mathrm{pH}$. Inhibitors of $\mathrm{pH}$-sensitive endosomal protease block $\mathrm{CoV}$ infection. Several different small compounds and molecules have been reported against virus infection. Amiodarone gets accumulated in the acidic organelles. Vacuoles on exposure to amiodarone shows alteration in intracellular organelles especially enlargement of late endosomes. In in-vitro environment, amiodarone inhibited coronavirus infection in Vero cells. At priori trypsin, cleavage of $\mathrm{S}$ protein is essential for a successful viral entry. However, trypsin cleavage also does not affect the efficacy of amiodarone [90-92].

\section{9-Novel Corona virus: Challenges}

In the RCSB database, only one PDB (PDB ID: 6LU7) is there on the 2019-nCoV which is in complex with $\mathrm{N} 3$ (inhibitor). The complete sequence of the $2019-\mathrm{nCoV}$ is available. However, it is only $95 \%$ similar to bat-SL-CoVZC45 and $88 \%$ to SIRS CoVZSc (nucleotide blast, NCBI). This highlights the amount of recombination processes or changes that occurred in the 2019-nCoV and changes in protein structural and functional levels [93].

\section{Clinical Trial Update on 2019-Ncov}

A total of 233 trials are registered till date in the Chinese Clinical Trial Registry (dated Feb 24, 2020, keywords 2019-nCov and COVID-19). Among the pharmacotherapeutic agents evaluated, some of the highlighted agents, which are being evaluated, are highdose Vitamin C, favipiravir, adalimumab, dihydroartemisininpiperaquine, leflunomide, dipyridamole, chloroquine or hydroxychloroquine, suramin sodium, lopinavir/ritonavir and arbidol (umifenovir) tablets, and IFN-alpha 2b. Other important agents being evaluated are Huo-Shen particles, Xiyanping injection, Shen-Fu injection, etc., many of which are from traditional Chinese medicines background. Use of stem cells is also evaluated frequently [94].

\section{CONCLUSION}

Drug discovery against the $\mathrm{CoV}$ is a challenging job owing to frequent recombination events. The development of a vaccine is another important aspect. We need more structural biology details and details of the life cycle of the CoV, which can speed up the drug/vaccine development process against CoV. Again, as a preventive measure, strict vigilance of viral changes in different hosts for prediction of an event is important.

\section{REFERENCES}

1. Yang, H., Bartlam, M., \& Rao, Z. (2006). Drug design targeting the main protease, the Achilles' heel of coronaviruses. Current pharmaceutical design, 12(35), 4573-4590.

2. Belouzard, S., Millet, J. K., Licitra, B. N., \& Whittaker, G. R. (2012). Mechanisms of coronavirus cell entry mediated by the viral spike protein. Viruses, 4(6), 1011-1033. 
3. Hilgenfeld, R. (2014). From SARS to MERS: crystallographic studies on coronaviral proteases enable antiviral drug design. The FEBS journal, 281(18), 4085-4096.

4. Chang, C. K., Lo, S. C., Wang, Y. S., \& Hou, M. H. (2016). Recent insights into the development of therapeutics against coronavirus diseases by targeting N protein. Drug discovery today, 21(4), 562-572.

5. Paules, C. I., Marston, H. D., \& Fauci, A. S. (2020). Coronavirus infections-more than just the common cold. Jama, 323(8), 707-708.

6. Saif, L. J. (2004). Animal coronaviruses: what can they teach us about the severe acute respiratory syndrome?. Revue scientifique et technique-Office international des épizooties, 23(2), 643-660.

7. Al-Osail, A. M., \& Al-Wazzah, M. J. (2017). The history and epidemiology of Middle East respiratory syndrome corona virus. Multidisciplinary

respiratory medicine, 12(1), 20.

8. J Alsaadi, E. A., \& Jones, I. M. (2019). Membrane binding proteins of coronaviruses. Future Virology, 14(4), 275-286.

9. McBride, R., Van Zyl, M., \& Fielding, B. C. (2014). The coronavirus nucleocapsid is a multifunctional protein. Viruses, 6(8), 2991-3018.

10. Li, F. (2016). Structure, function, and evolution of coronavirus spike proteins. Annual review of virology, 3, 237-261.

11. Guo, Y., Korteweg, C., McNutt, M. A., \& Gu, J. (2008). Pathogenetic mechanisms of severe acute respiratory syndrome. Virus research, 133(1), 412.

12. Gu, J., \& Korteweg, C. (2007). Pathology and pathogenesis of severe acute respiratory syndrome. The American journal of pathology, 170(4), 1136-1147.

13. Ding, Y., He, L. I., Zhang, Q., Huang, Z., Che, X., Hou, J., ... \& Geng, J. (2004). Organ distribution of severe acute respiratory syndrome (SARS) associated coronavirus (SARS- CoV) in SARS patients: implications for pathogenesis and virus transmission pathways. The Journal of Pathology: A Journal of the Pathological Society of Great Britain and Ireland, 203(2), 622-630.

14. Li, W., Moore, M. J., Vasilieva, N., Sui, J., Wong, S. K., Berne, M. A., ... \& Choe, H. (2003). Angiotensin-converting enzyme 2 is a functional receptor for the SARS coronavirus. Nature, 426(6965), 450-454.

15. Mubarak, A., Alturaiki, W., \& Hemida, M. G. (2019). Middle east respiratory syndrome coronavirus (MERS-CoV): infection, immunological response, and vaccine development. Journal of immunology research, 2019:1-11.

16. Te Velthuis, A. J., Van Den Worm, S. H., \& Snijder, E. J. (2012). The SARS-coronavirus nsp7+ nsp8 complex is a unique multimeric RNA polymerase capable of both de novo initiation and primer extension. Nucleic acids research, 40(4), 1737-1747.

17. Stobart, C. C., Sexton, N. R., Munjal, H., Lu, X., Molland, K. L., Tomar, S., ... \& Denison, M. R. (2013). Chimeric exchange of coronavirus nsp5 proteases (3CLpro) identifies common and divergent regulatory determinants of protease activity. Journal of virology,87(23), 1261112618.

18. Wang, H., Xue, S., Yang, H., \& Chen, C. (2016). Recent progress in the discovery of inhibitors targeting coronavirus proteases. Virologica Sinica, 31(1), 24-30.

19. Egloff, M. P., Ferron, F., Campanacci, V., Longhi, S., Rancurel, C., Dutartre, H., ... \& Canard, B. (2004). The severe acute respiratory syndromecoronavirus replicative protein nsp9 is a singlestranded RNA-binding subunit unique in the RNA virus world. Proceedings of the National Academy of Sciences, 101(11), 3792-3796.

20. Hu, T., Chen, C., Li, H., Dou, Y., Zhou, M., Lu, D., ... \& Singh, N. (2017). Structural basis for dimerization and RNA binding of avian infectious bronchitis virus nsp9. Protein Science, 26(5), 1037-1048.

21. Bouvet, M., Lugari, A., Posthuma, C. C., Zevenhoven, J. C., Bernard, S., Betzi, S., ... \& Pfefferle, S. (2014). Coronavirus Nsp10, a critical co-factor for activation of multiple replicative enzymes. Journal of Biological Chemistry, 289(37), 25783-25796.

22. Narayanan, K., Maeda, A., Maeda, J., \& Makino, S. (2000). Characterization of the coronavirus M protein and nucleocapsid interaction in infected cells. Journal of virology, 74(17), 8127-8134.

23. De Wit, E., Van Doremalen, N., Falzarano, D., \& Munster, V. J. (2016). SARS and MERS: recent insights into emerging coronaviruses. Nature Reviews Microbiology, 14(8), 523-534.

24. Nieto-Torres, J. L., DeDiego, M. L., Álvarez, E., Jiménez-Guardeño, J. M., Regla-Nava, J. A., Llorente, M., .. \& Enjuanes, L. (2011). Subcellular location and topology of severe acute respiratory syndrome coronavirus envelope protein. Virology, 415(2), 69-82.

25. Du, L., He, Y., Zhou, Y., Liu, S., Zheng, B. J., \& Jiang, S. (2009). The spike protein of SARS$\mathrm{CoV}$ - a target for vaccine and therapeutic development. Nature Reviews Microbiology, 7(3), 226-236.

26. Lin, S. Y., Liu, C. L., Chang, Y. M., Zhao, J., Perlman, S., \& Hou, M. H. (2014). Structural basis for the identification of the $\mathrm{N}$-terminal domain of coronavirus nucleocapsid protein as an antiviral target. Journal of medicinal chemistry,57(6), 2247-2257.

27. Shimamoto, Y., Hattori, Y., Kobayashi, K., Teruya, K., Sanjoh, A., Nakagawa, A., ... \& Akaji, K. (2015). Fused-ring structure of 
decahydroisoquinolin as a novel scaffold for SARS 3CL protease inhibitors. Bioorganic \& medicinal chemistry, 23(4), 876-890.

28. Three Drugs Fairly Effective on Novel Coronavirus at Cellular Level-Xinhua. Available from: http://www.xinhuanet.com/english/202001/30/c_138742163.htm.

29. Coronavirus Outbreak: Cocktail of Flu, HIV Drugs Appears to Help Fight Virus, Say Thai Doctors. India Today; 03 February, 2020.

30. Bank RPD. RCSB PDB-Unreleased Structures for 3V3P.

31. Báez-Santos, Y. M., Barraza, S. J., Wilson, M. W., Agius, M. P., Mielech, A. M., Davis, N. M., ... \& Mesecar, A. D. (2014). X-ray structural and biological evaluation of a series of potent and highly selective inhibitors of human coronavirus papain-like proteases. Journal of medicinal chemistry, 57(6), 2393-2412.

32. Ghosh, A. K., Takayama, J., Rao, K. V., Ratia, K., Chaudhuri, R., Mulhearn, D. C., ... \& Johnson, M. E. (2010). Severe acute respiratory syndrome coronavirus papain-like novel protease inhibitors: design, synthesis, protein- ligand X-ray structure and biological evaluation. Journal of medicinal chemistry, 53(13), 4968-4979.

33. Ratia, K., Saikatendu, K. S., Santarsiero, B. D., Barretto, N., Baker, S. C., Stevens, R. C., \& Mesecar, A. D. (2006). Severe acute respiratory syndrome coronavirus papain-like protease: structure of a viral deubiquitinating enzyme. Proceedings of the National Academy of Sciences, 103(15), 5717-5722.

34. Yang, H., Yang, M., Ding, Y., Liu, Y., Lou, Z., Zhou, Z., ... \& Gao, G. F. (2003). The crystal structures of severe acute respiratory syndrome virus main protease and its complex with an inhibitor. Proceedings of the National Academy of Sciences, 100(23), 13190-13195.

35. Chuck, C. P., Chen, C., Ke, Z., Wan, D. C. C., Chow, H. F., \& Wong, K. B. (2013). Design, synthesis and crystallographic analysis of nitrilebased broad-spectrum peptidomimetic inhibitors for coronavirus 3C-like proteases. European journal of medicinal chemistry, 59, 1-6.

36. Chuck, C. P., \& Wong, K. B. Crystal Structure of Human Coronavirus NL63 3C-like Protease.

37. Wang, F., Chen, C., Tan, W., Yang, K., \& Yang, H. (2016). Structure of main protease from human coronavirus NL63: insights for wide spectrum anti-coronavirus drug design. Scientific reports, 6 , 22677.

38. Liu, X., Zhang, B., Jin, Z., Yang, H., \& Rao, Z. The Crystal Structure of 2019-nCoV Main Protease in Complex with an Inhibitor N3.

39. Xia, S., Yan, L., Xu, W., Agrawal, A. S., Algaissi, A., Tseng, C. T. K., ... \& Jiang, S. (2019). A pancoronavirus fusion inhibitor targeting the HR1 domain of human coronavirus spike. Science advances, 5(4), eaav4580.
40. Yuan, Y., Cao, D., Zhang, Y., Ma, J., Qi, J., Wang, Q., ... \& Zhang, X. (2017). Cryo-EM structures of MERS-CoV and SARS-CoV spike glycoproteins reveal the dynamic receptor binding domains. Nature communications, 8(1), 1-9.

41. Gui, M., Song, W., Zhou, H., Xu, J., Chen, S., Xiang, Y., \& Wang, X. (2017). Cryo-electron microscopy structures of the SARS-CoV spike glycoprotein reveal a prerequisite conformational state for receptor binding. Cell research, 27(1), 119-129.

42. Park, Y. J., Walls, A. C., Wang, Z., Sauer, M. M., Li, W., Tortorici, M. A., ... \& Veesler, D. (2019). Structures of MERS-CoV spike glycoprotein in complex with sialoside attachment receptors. Nature structural \& molecular biology, 26(12), 1151-1157.

43. Song, W., Gui, M., Wang, X., \& Xiang, Y. (2018). Cryo-EM structure of the SARS coronavirus spike glycoprotein in complex with its host cell receptor ACE2. PLoS pathogens, 14(8), e1007236.

44. Wu, K., Peng, G., Wilken, M., Geraghty, R., \& Li, F. SARS coronavirus: Mechanism of host receptor adaptation and rational prediction of future evolution.

45. Prabakaran, P., Xiao, X., \& Dimitrov, D. S. (2004). A model of the ACE2 structure and function as a SARS-CoV receptor. Biochemical and biophysical research communications, 314(1), 235-241.

46. Jeffers, S. A., Tusell, S. M., Gillim-Ross, L., Hemmila, E. M., Achenbach, J. E., Babcock, G. J., ... \& Ambrosino, D. M. (2004). CD209L (LSIGN) is a receptor for severe acute respiratory syndrome coronavirus. Proceedings of the National Academy of Sciences, 101(44), 1574815753.

47. Yang, Z. Y., Huang, Y., Ganesh, L., Leung, K., Kong, W. P., Schwartz, O., ... \& Nabel, G. J. (2004). pH-dependent entry of severe acute respiratory syndrome coronavirus is mediated by the spike glycoprotein and enhanced by dendritic cell transfer through DC-SIGN. Journal of virology, 78(11), 5642-5650.

48. Han, D. P., Lohani, M., \& Cho, M. W. (2007). Specific asparagine-linked glycosylation sites are critical for DC-SIGN-and L-SIGN-mediated severe acute respiratory syndrome coronavirus entry. Journal of virology, 81(21), 12029-12039.

49. Hu, H., Li, L., Kao, R. Y., Kou, B., Wang, Z., Zhang, L., ... \& Cui, L. (2005). Screening and identification of linear B-cell epitopes and entryblocking peptide of severe acute respiratory syndrome (SARS)-associated coronavirus using synthetic overlapping peptide library. Journal of combinatorial chemistry, 7(5), 648-656.

50. Han, D. P., Penn-Nicholson, A., \& Cho, M. W. (2006). Identification of critical determinants on ACE2 for SARS-CoV entry and development of a potent entry inhibitor. Virology, 350(1), 15-25. 
51. Vincent, M. J., Bergeron, E., Benjannet, S., Erickson, B. R., Rollin, P. E., Ksiazek, T. G., ... \& Nichol, S. T. (2005). Chloroquine is a potent inhibitor of SARS coronavirus infection and spread. Virology journal, 2(1), 1-10.

52. Adedeji, A. O., Severson, W., Jonsson, C., Singh, K., Weiss, S. R., \& Sarafianos, S. G. (2013). Novel inhibitors of severe acute respiratory syndrome coronavirus entry that act by three distinct mechanisms. Journal of virology, 87(14), 8017-8028.

53. Kao, R. Y., Tsui, W. H., Lee, T. S., Tanner, J. A., Watt, R. M., Huang, J. D., ... \& He, T. (2004). Identification of novel small-molecule inhibitors of severe acute respiratory syndrome-associated coronavirus by chemical genetics. Chemistry \& biology, 11(9), 1293-1299.

54. Wu, C. J., Huang, H. W., Liu, C. Y., Hong, C. F., \& Chan, Y. L. (2005). Inhibition of SARS-CoV replication by siRNA. Antiviral research,65(1), 45-48.

55. Walls, A. C., Xiong, X., Park, Y. J., Tortorici, M. A., Snijder, J., Quispe, J., ... \& Zambon, M. (2019). Unexpected receptor functional mimicry elucidates activation of coronavirus fusion. Cell, 176(5), 1026-1039.

56. Prabakaran, P., Gan, J., Feng, Y., Zhu, Z., Choudhry, V., Xiao, X., ... \& Dimitrov, D. S. (2006). Structure of severe acute respiratory syndrome coronavirus receptor-binding domain complexed with neutralizing antibody. Journal of Biological Chemistry, 281(23), 15829-15836.

57. Okada, M., Takemoto, Y., Okuno, Y., Hashimoto, S., Yoshida, S., Fukunaga, Y., ... \& Kanamaru, N. (2005). The development of vaccines against SARS corona virus in mice and SCID-PBL/hu mice. Vaccine, 23(17-18), 2269-2272.

58. Kuo, L., Hurst, K. R., \& Masters, P. S. (2007). Exceptional flexibility in the sequence requirements for coronavirus small envelope protein function. Journal of virology, 81(5), 22492262.

59. Venkatagopalan, P., Daskalova, S. M., Lopez, L. A., Dolezal, K. A., \& Hogue, B. G. (2015). Coronavirus envelope $(\mathrm{E})$ protein remains at the site of assembly. Virology, 478, 75-85.

60. Schoeman, D., \& Fielding, B. C. (2019). Coronavirus envelope protein: current knowledge. Virology journal, 16(1), 1-22.

61. Arbely, E., Khattari, Z., Brotons, G., Akkawi, M., Salditt, T., \& Arkin, I. T. (2004). A highly unusual palindromic transmembrane helical hairpin formed by SARS coronavirus $\mathrm{E}$ protein. Journal of molecular biology, 341(3), 769-779.

62. Pervushin, K., Tan, E., Parthasarathy, K., Lin, X., Jiang, F. L., Yu, D., ... \& Torres, J. (2009). Structure and inhibition of the SARS coronavirus envelope protein ion channel. PLoS Pathog, 5(7), e1000511.
63. Hogue, B. G., \& Machamer, C. E. (2007). Coronavirus structural proteins and virus assembly. Nidoviruses, 179-200.

64. Arndt, A. L., Larson, B. J., \& Hogue, B. G. (2010). A conserved domain in the coronavirus membrane protein tail is important for virus assembly. Journal of virology,84(21), 11418 11428.

65. M-Membrane Protein-Human SARS Coronavirus (SARS-CoV)-M Gene and Protein.

66. Wang, Y., \& Liu, L. (2016). The membrane protein of severe acute respiratory syndrome coronavirus functions as a novel cytosolic pathogen-associated molecular pattern to promote beta interferon induction via a Toll-like-receptorrelated mechanism. MBio, 7(1):e01872-15.

67. Chang, C. K., Hou, M. H., Chang, C. F., Hsiao, C. D., \& Huang, T. H. (2014). The SARS coronavirus nucleocapsid protein-forms and functions. Antiviral research, 103, 39-50.

68. Surjit, M., Liu, B., Chow, V. T., \& Lal, S. K. (2006). The nucleocapsid protein of severe acute respiratory syndrome-coronavirus inhibits the activity of cyclin-cyclin-dependent kinase complex and blocks $\mathrm{S}$ phase progression in mammalian cells. Journal of Biological Chemistry, 281(16), 10669-10681.

69. Chang, C. K., Jeyachandran, S., Hu, N. J., Liu, C. L., Lin, S. Y., Wang, Y. S., ... \& Hou, M. H. (2016). Structure-based virtual screening and experimental validation of the discovery of inhibitors targeted towards the human coronavirus nucleocapsid biosystems, 12(1), 59-66.

70. Roh, C. (2012). A facile inhibitor screening of SARS coronavirus $\mathrm{N}$ protein using nanoparticlebased RNA oligonucleotide. International journal of nanomedicine, 7, 2173-2179.

71. Lo, Y. S., Lin, S. Y., Wang, S. M., Wang, C. T., Chiu, Y. L., Huang, T. H., \& Hou, M. H. (2013). Oligomerization of the carboxyl terminal domain of the human coronavirus 229E nucleocapsid protein. FEBS letters, 587(2), 120-127.

72. Cheung, Y. K., Cheng, S. C. S., Sin, F. W. Y., Chan, K. T., \& Xie, Y. (2007). Induction of T-cell response by a DNA vaccine encoding a novel HLA-A* 0201 severe acute respiratory syndrome coronavirus epitope. Vaccine, 25(32), 6070-6077.

73. Zhao, J., Huang, Q., Wang, W., Zhang, Y., Lv, P., \& Gao, X. M. (2007). Identification and characterization of dominant helper T-cell epitopes in the nucleocapsid protein of severe acute respiratory syndrome coronavirus. Journal of virology, 81(11), 6079-6088.

74. Lindner, H. A., Fotouhi-Ardakani, N., Lytvyn, V., Lachance, P., Sulea, T., \& Ménard, R. (2005). The papain-like protease from the severe acute respiratory syndrome coronavirus is a 
deubiquitinating enzyme. Journal of virology, 79(24), 15199-15208.

75. Jo, S., Kim, S., Shin, D. H., \& Kim, M. S. (2020). Inhibition of SARS-CoV 3CL protease by flavonoids. Journal of enzyme inhibition and medicinal chemistry, 35(1), 145-151.

76. Hu, T., Zhang, Y., Li, L., Wang, K., Chen, S., Chen, J., ... \& Shen, X. (2009). Two adjacent mutations on the dimer interface of SARS coronavirus 3C-like protease cause different conformational changes in crystal structure. Virology, 388(2), 324-334.

77. Hsu, M. F., Kuo, C. J., Chang, K. T., Chang, H. C., Chou, C. C., Ko, T. P., ... \& Liang, P. H. (2005). Mechanism of the maturation process of SARS-CoV 3CL protease. Journal of Biological Chemistry, 280(35), 31257-31266.

78. Barretto, N., Jukneliene, D., Ratia, K., Chen, Z., Mesecar, A. D., \& Baker, S. C. (2005). The papain-like protease of severe acute respiratory syndrome coronavirus has deubiquitinating activity. Journal of virology,79(24), 1518915198.

79. Turlington, M., Chun, A., Tomar, S., Eggler, A., Grum-Tokars, V., Jacobs, J., ... \& Baez-Santos, Y. M. (2013). Discovery of N-(benzo [1, 2, 3] triazol1-yl)-N-(benzyl) acetamido) phenyl) carboxamides as severe acute respiratory syndrome coronavirus (SARS-CoV) 3CLpro inhibitors: identification of ML300 and noncovalent nanomolar inhibitors with an induced-fit binding. Bioorganic \& medicinal chemistry letters, 23(22), 6172-6177.

80. Jacobs, J., Grum-Tokars, V., Zhou, Y., Turlington, M., Saldanha, S. A., Chase, P., ... \& Mielech, A. M. (2013). Discovery, synthesis, and structurebased optimization of a series of N-(tert-butyl)-2(N-arylamido)-2-(pyridin-3-yl) acetamides (ML188) as potent noncovalent small molecule inhibitors of the severe acute respiratory syndrome coronavirus (SARS-CoV) 3CL protease. Journal of medicinal chemistry, 56(2), 534-546.

81. Perera, K. D., Rathnayake, A. D., Liu, H., Pedersen, N. C., Groutas, W. C., Chang, K. O., \& Kim, Y. (2019). Characterization of amino acid substitutions in feline coronavirus 3C-like protease from a cat with feline infectious peritonitis treated with a protease inhibitor. Veterinary microbiology, 237, 108398.

82. Yang, H., Xie, W., Xue, X., Yang, K., Ma, J., Liang, W., ... \& Hilgenfeld, R. (2005). Design of wide-spectrum inhibitors targeting coronavirus main proteases. PLoS Biol, 3(10), e324.

83. Liu, X., \& Wang, X. J. (2020). Potential inhibitors against 2019-nCoV coronavirus M protease from clinically approved medicines. Journal of Genetics and Genomics, 47(2), 119.
84. Han, Y. S., Chang, G. G., Juo, C. G., Lee, H. J., Yeh, S. H., Hsu, J. T. A., \& Chen, X. (2005). Papain-like protease 2 (PLP2) from severe acute respiratory syndrome coronavirus (SARS-CoV): expression, purification, characterization, and inhibition. Biochemistry, 44(30), 10349-10359.

85. Lim, J., Jeon, S., Shin, H. Y., Kim, M. J., Seong, Y. M., Lee, W. J., ... \& Park, S. J. (2020). Case of the index patient who caused tertiary transmission of COVID-19 infection in Korea: the application of lopinavir/ritonavir for the treatment of COVID19 infected pneumonia monitored by quantitative RT-PCR. Journal of Korean medical science, 35(6):e79.

86. Zeng, Q., Langereis, M. A., Van Vliet, A. L., Huizinga, E. G., \& De Groot, R. J. (2008). Structure of coronavirus hemagglutinin-esterase offers insight into corona and influenza virus evolution. Proceedings of the National Academy of Sciences, 105(26), 9065-9069.

87. Frick, D. N., \& Lam, A. M. I. (2006). Understanding helicases as a means of virus control. Current pharmaceutical design,12(11), 1315-1338.

88. Karpe, Y. A., \& Lole, K. S. (2010). NTPase and 5' to 3' RNA duplex-unwinding activities of the hepatitis $\mathrm{E}$ virus helicase domain. Journal of virology, 84(7), 3595-3602.

89. Banerjee, T., Aggarwal, M., Sommers, J. A., \& Brosh Jr, R. M. (2016). Biochemical and cell biological assays to identify and characterize DNA helicase inhibitors. Methods, 108, 130-141.

90. Simmons, G., Gosalia, D. N., Rennekamp, A. J., Reeves, J. D., Diamond, S. L., \& Bates, P. (2005). Inhibitors of cathepsin L prevent severe acute respiratory syndrome coronavirus entry. Proceedings of the National Academy of Sciences, 102(33), 11876-11881.

91. Bertram, S., Glowacka, I., Müller, M. A., Lavender, H., Gnirss, K., Nehlmeier, I., ... \& Soilleux, E. J. (2011). Cleavage and activation of the severe acute respiratory syndrome coronavirus spike protein by human airway trypsin-like protease. Journal of virology,85(24), 13363 13372.

92. Stadler, K., Ha, H. R., Ciminale, V., Spirli, C., Saletti, G., Schiavon, M., ... \& Baritussio, A. (2008). Amiodarone alters late endosomes and inhibits SARS coronavirus infection at a postendosomal level. American journal of respiratory cell and molecular biology, 39(2), 142-149.

93. Wuhan Seafood Market Pneumonia Virus Isolate Wuhan-Hu-1, Complete Genome; 2020.

94. Chinese Clinical Trial Register (ChiCTR)-The World Health Organization International Clinical Trials Registered Organization Registered Platform. 